TP Periodica Polytechnica

Mechanical Engineering

59(4), pp. 189-198, 2015

DOI: 10.3311/PPme.8327

Creative Commons Attribution (i)

RESEARCH ARTICLE

\section{Vibration Mitigation of Shazand Railway Bridge Induced by Train Using Tuned Mass Damper (TMD)}

\author{
Reza Latifi ${ }^{1 *}$, Reza Razani ${ }^{2}$
}

Received 13 June 2015; accepted after revision 03 September 2015

\section{Abstract}

In the last two decades, tuned mass damper has been used as a passive control method against earthquakes on tall buildings and bridges. In this paper, the effect of tuned mass damper system on the seismic behavior of 10 story structure with moment frame has been investigated taking into account the floor rigidity. In addition, the effect of TMD system is investigated on Shazand Railway Bridge located in Markazi province, Iran in north to south-west railway. The bridge consists of ten spans. In 1984, during Iran-Iraq war, that's main span, which has a length of $72 \mathrm{~m}$, was attacked and severely damaged. Eight month later, damaged span replaced with a steel deck. The deck is straight in plan, but the railway is curved and thi. causes eccentricity. Excessive vibration was observed durin the train passage. Although the bridge was retrofitted in two stages, the problem has not been solved $y$ speed should be reduced to around $10 \mathrm{k}$ excessive vibration. The present studv ness of tuned mass damper (TMD) in reduc vibrations of Shazand Railway Bxidge. A three dimensional finite-element model of the idge is developed and dynamic time history analyses under train passage in both as-built and passively controlled with TMD are conducted Sensitivity analyses are performed to demonstrate the effects of the damper parameters on structural response. The results show that considerable reduction in acceleration response of the bridge can be achieyed by employing proper TMD.

${ }^{1}$ School of Civil Engineering, Shiraz University of Technology, Shiraz, Iran

${ }^{2}$ School of Civil Engineering, Shiraz University, Shiraz, Iran

"Corresponding author, e-mail: R.Latifi@sutech.ac.ir

\section{Introduction}

Given recent advances against earthquakes and passive control syste and weaknesses

TMD, like ot

\section{erconts} earthquake-prone cou the need for energy dissipation in the load-bearing elements of a structure against laterak loads. This decrease is achieved by movement of a heavy load on the load-bearing elements of the structure. TMD operation is based on dynamic vibration absorbers invented by Frahm in 1909. In 1956, Den Hartog [2] completed and corrected Frahm's work and later investiated damped and undamped dynamic absorber systems with damping of the original system. With the aim of improving the erformance of dynamic vibration absorbers, Snowdon (1960) investigated solid absorber behavior in reducing the main system response. Results of this study showed that the dynamic absorber that used materials with stiffness proportional to frequency and a constant damping factor could significantly reduce the resonant vibration in the main system. In 1977, Jennige and Frohrib investigated a translatory-rotary absorber system numerically to control both bending and torsional modes in a building [3]. Most early studies focused on the use of dynamic absorbers in mechanical systems where only one operating frequency in resonance with the fundamental frequency of the machine. Since building structures are affected by environmental and natural loads, they have different frequency components. Selecting a TMD system can be based on several important parameters [4] such as efficiency, compactness and dimensions; economic cost of the system; implementation and installation costs; and maintenance and security of the system for buildings. In engineering design of a TMD, the dynamic response that can be achieved in practice is applied with a series of implementation considerations.

Shazand Railway Bridge is one of the most famous historical stone arch bridges in Iran. Shazand Railway Bridge was constructed in 1937 and opened to traffic in 1939. This bridge is located in of Markazi Railway route, between Samangan and noorabad. The bridge is near Shazand station, and it is 

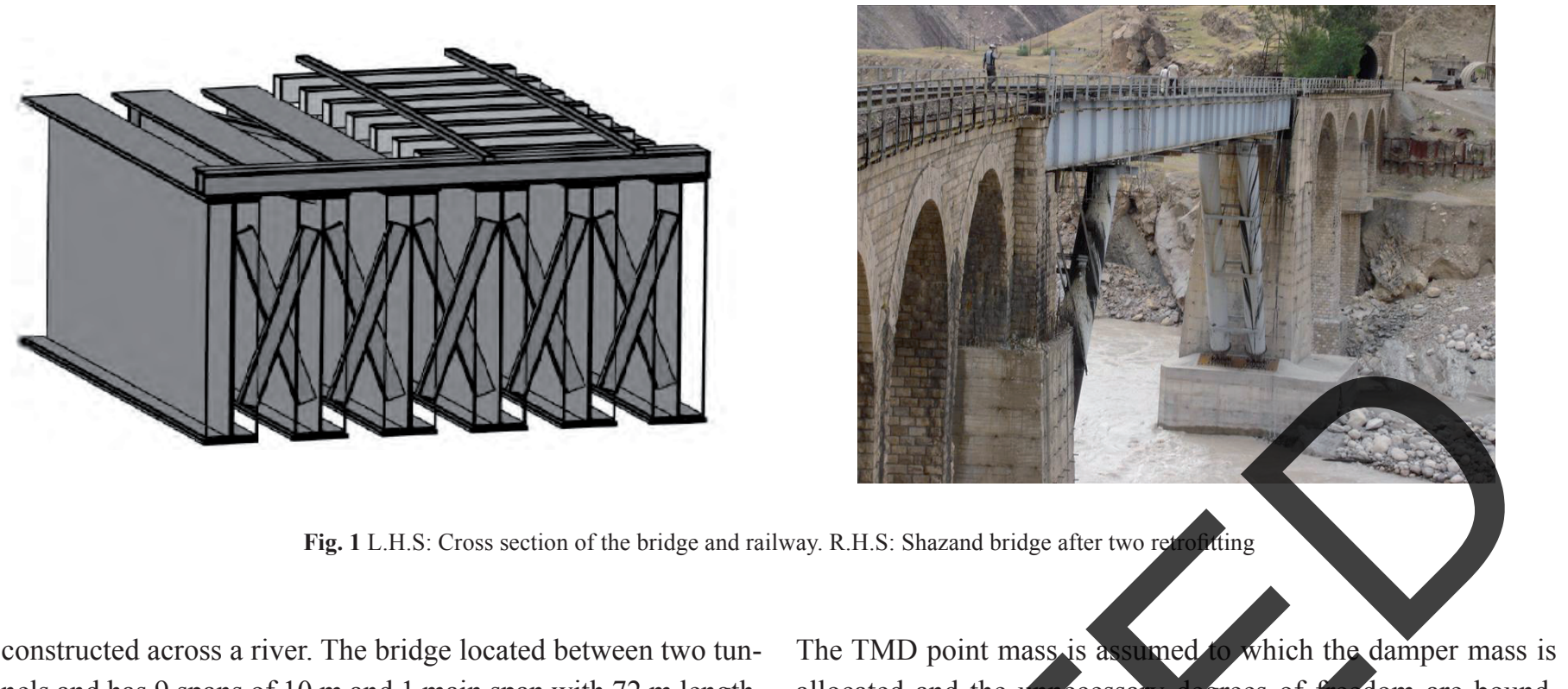

constructed across a river. The bridge located between two tunnels and has 9 spans of $10 \mathrm{~m}$ and 1 main span with $72 \mathrm{~m}$ length. Railway of North to Southwest is one of the strategic routes of Iran. This route has a single rail line and has a light terrific density. This bridge had a significant effect in War between Iran and Iraq. In that war, the bridge repeatedly attacked by air strike but was not damaged significantly. In 1987, air attack caused severe failure of the main span of the bridge and the railroad was disconnected. It was necessary to reopen the supply route immediately. New steel deck designed, and implanted in 1990. The steel deck is straight in a plan, but the railway is curved and this caused eccentricity. Fig. 1 shows cross-section of the bridge and eccentricity of the rail line and bridge after two retrofitting The length of the steel deck is $72 \mathrm{~m}$ and depth steel plate girders connected by cross brace and chord. A each abutment, the deck rests on six non-seismic elastomeric pads. The steel bridge had excessive vibration cue trains passing; therefore, speed of trains limited to 6 kilometres per hour. During the war, the steel bridge was attacked severa times, but was not seriously damaged. After the war, the bridge retrofitted in two stages. In the first stage, the bridge post-tensioned with 16 cables to reduce negative stresses. In the second stage, four oblique columns added to the bridge. These columns divided the bridge to 3 spans with length of 15,42 and $15 \mathrm{~m}$.

The problem did not solve entirely with these retrofitting, just
speed of trains arose to 10 kilometers per hour. Field tests on
the bridge showed that the acceleration of middle of the bridge reaches more than $1 \mathrm{~g}$. The ratio of maximum displacement of the system with damper to that of the system without damper was largely dependent on the form of earthquake input records. In the computer modeling (with SAP2000) of the TMD system, Non-Linear Link was used. Two Nllink members with damper character was placed on each other between the mass of TMD and the TMD junction with the structure. One of these has a stiffness equal to the stiffness needed in the TMD and a damping of zero and the other has a damping equal to that of the TMD and a stiffness of 0.01 (to prevent computational error). allocated and the unnecessary degrees of freedom are bound. The behavior of the structure is estimated in the range of linear behavior. Combined structure-TMD system is shown in Fig. 2.

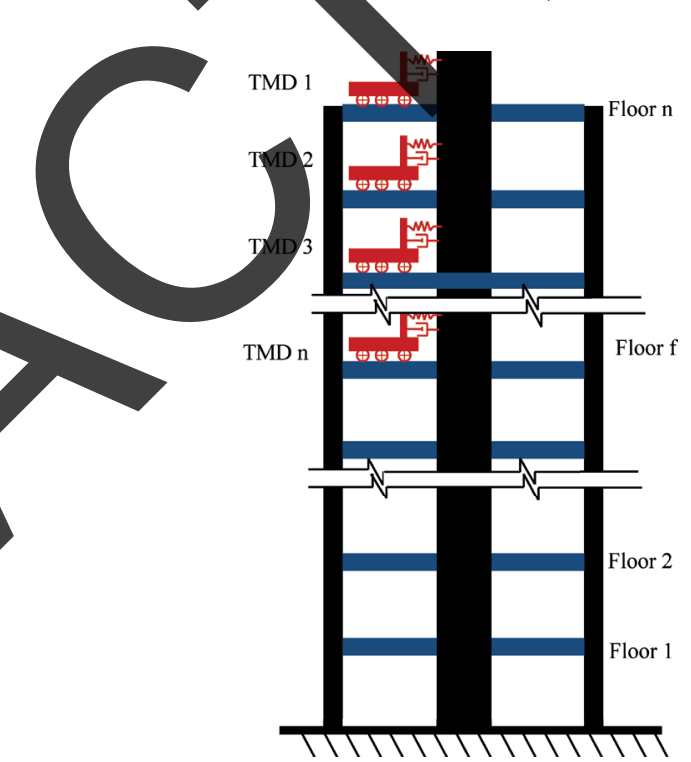

Fig. 2 The combined structure-TMD system

Using Tuned Mass Damper (TMD) is one of the techniques to suppress vibrations. TMD is a classical control device and it is made of a mass, a spring and a viscous damper. The concept of TMD was proposed by Frahm [1]. Den Hartog added a damper to Frahm's devices and proposed an optimal design for TMDs under harmonic load [2]. Philosophy of using TMD is a reduction of structural vibration energy. This reduction is accomplished by transferring some of the vibration energy of structure to the TMD. This devise has a variety of merits; it has permanent servise time, requires easy management and maintenance, and it can be simply incorporated into an existing structure with less interference on main performance of the structure. In summary, its advantages include compactness reliability, efficiency and low cost.TMDs have been extensively studied and applied to attenuate wind and earthquake induced 
vibrations. Most of the theoretical analyses, experimental researches and practical uses have been shown that TMD is an effective to suppress structural vibrations. Several researchers have investigated using of TMD in reducing the vibration of a bridge under traffic loads. Kwon et al. studied the use of TMD to suppress vibrations of a three-span bridge under TGV train passage. They concluded that TMD can reduce $21 \%$ of maximum displacement, and quickly suppress the free vibrations [3]. Wang et al. created numerical and analytical of Taiwan High-Speed Railway and investigated the performance of TMD to suppress the train-induced vibrations. The numerical results showed TMD can reduce up to $40 \%$ of acceleration of the moderately long bridge under train's passage. They concluded that interaction effect between bridge and train is of no significant effect on TMD's performance [4]. In present study the effectiveness of TMD in reducing train-induced vibrations of Shazand Railway Bridge is addressed. A three dimensional finite-element model of the bridge is developed and dynamic time history analyses under train passage in both as-built and passively controlled with TMD are conducted. Sensitivity analyses are performed to demonstrate the effects of the damper parameters on structural response.

\section{Equations of Motion of the Bridge and TMD}

For the formulation of bridge responses, these assumptions are used: 1 - the bridge is idealized as having permanent stif ness in its length, 2- train is modeled as moving forces, 3- th train moves at a constant speed on the bridge, 4-only vertica modes of the bridge considered. The equation of motion can be expressed as

$$
M \dot{z}(x, \mathrm{t})+C \dot{z}(x, t)+\mathrm{Kz}(x, t) \Rightarrow F_{v}
$$
matrix of damping, $\mathrm{K}=$ main which $\mathrm{M}=$ matrix of mass and $F_{T}(t)$ are interaction force be-
between TMD and the bridge, retrix of stiffness and $F_{v}(t)$ tween bridge and train and between
spectively. In all cases initial set of loads are considered to be these of the first axle of the train when it enters the bridge. Let $a i$ be the longitudinal distance from the $i$ th train load set to the initial train load set on the bridge Rand $\mathrm{K}$ stand for the number of first and last train axles on the bridge. At time $t, F_{v}(x, t)$

$$
F_{v}(x, t)=\sum_{i=R}^{k} \delta\left[x-\left(v t-a_{i}\right)\right] \times p_{i}
$$

where $\delta=$ dirac delta function, $v=$ speed of a train $p_{i}=$ static load of $i$ th wheel of train, $C_{T}$ and $K_{T}=$ damping and spring constant of the TMD, respectively, $z\left(\frac{L}{2}, \mathrm{t}\right)=$ vertical vibration displacement of middle of the bridge, $y(t)=$ vertical vibration displacement of the TMD and a dot represents derivative with respect to time.
Jianzhong et al. investigated a simply supported girder bridge under high-speed trains with an emphasis on the resonant vibration. They proposed Eq. (4) for resonant speed of trains and concluded that the number of wheel-axle of train passage across the bridge is also an important factor in bridge resonant vibration [5].

$$
v=\frac{\omega}{2 \pi j} L_{v} \quad(j=1,2,3, \ldots)
$$

in this equation $L_{v}=$ distance between train axles, $\omega=$ fundamental frequency of the bridge.

\section{Optimum parameters of Tuned Mass Damper}

Den Hartog proposed formulas for obtaining optimum parameters of TMD. These formulas are obtained for reduction responses of structure with single degree of freedom under harmonic load excitation [2]. Den Hartog formulations are given as $f_{\text {opt }}=\frac{1}{1+\mu}$

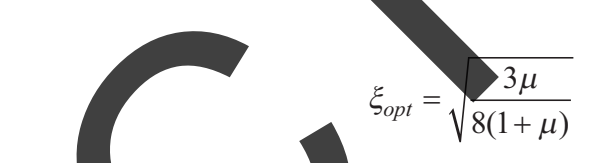
where $\mu$ is mass ratio of TMD. Having $\xi_{\text {opt }}$ and $f$, optimum values of damping coefficient $C_{T}$ and stiffness $K_{T}$ of the TMD can calculated as

$$
\begin{gathered}
K_{o p t}=f_{o p t}^{2} \omega_{s}^{2} m \\
C_{o p t}=2 \xi_{O P T} \omega_{s} m
\end{gathered}
$$

nhich $\omega_{s}=$ Main structure frequency, $m=$ TMD mass.

Sadak et al. proposed TMD optimum parameter for multi degree of freedom (MDOF) structure under earthquake excitation. Results shown that with the use of optimum parameter, significant reduction of structural responses can be achieved [6]. Sadak et al. formulations are given as

$$
\begin{gathered}
f_{\text {opt }}=\frac{1}{1+\mu \Phi}\left[1-\beta \sqrt{\frac{\mu \Phi}{1+\mu \Phi}}\right] \\
\xi=\Phi\left[\frac{\beta}{1+\mu}+\sqrt{\frac{\mu}{1+\mu}}\right]
\end{gathered}
$$

where $\beta$ is the damping ratio of main structure, $\Phi$ is the amplitude of fundamental mode of vibration for a unit modal participation factor computed at location of TMD and $\mu$ is the mass ratio for MDOF structure. $\mu$ Can be calculated as

$$
\mu=\frac{m}{\Phi_{n}^{T} M \Phi_{n}}
$$

in which $\mathrm{m}$ is the TMD mass, $M$ is the mass matrix of structure and $\Phi_{n}$ is fundamental mode shape normalized to have a unit participation factor. 


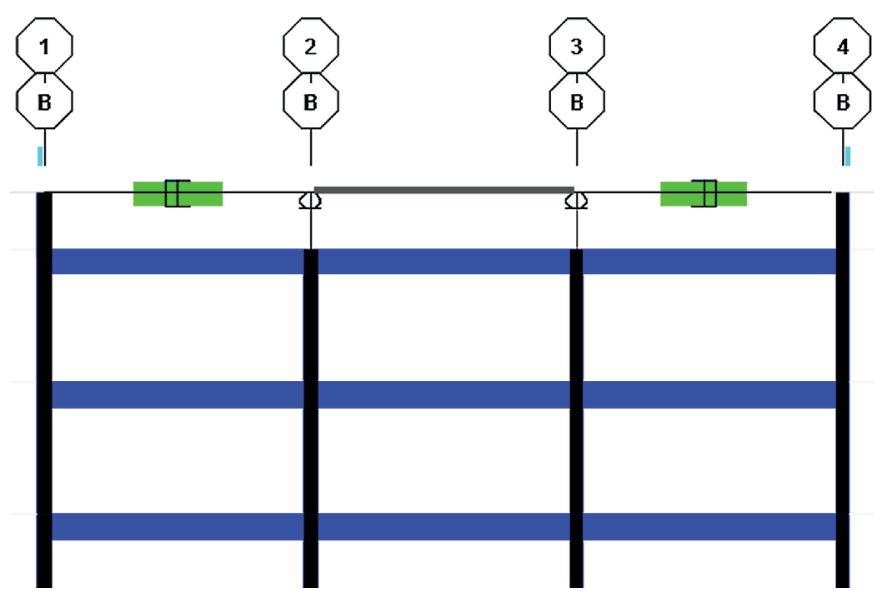

Fig. 3 Right Hand Side(R.H.S.): The building plan and L.H.S.: TMD Sy

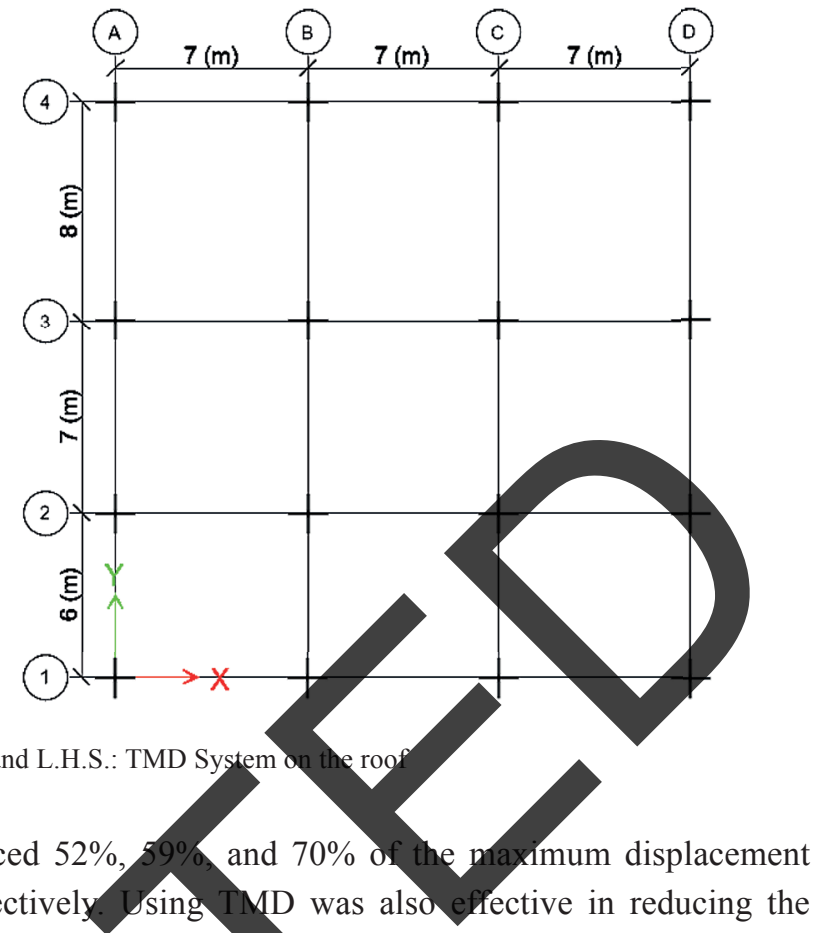

base shears. As seen in Fig. 6 and 7, in El Centro earthquake, using TMDs of 3\%, 5\%, and 10\% reduced 33\%, 39\%, and 44\% of the base shear respectively. In Manjil-Rudbar earthquake, it reduced $10 \%, 20 \%$, and $35 \%$ of the base shear respectively. As can be seen, using the TMD was effective in reducing the amount of the base shear. In addition to balancing the structural vibration the TMD reduced the amount of shear force ate the structure base. This will require the use of lighter sections in the structure frames.

However, if the structure has a damping of 5\% and a period of 2.54 seconds, the optimum damper parameters in Table 1 for $\xi_{\mathrm{s}}=5 \%, \mu=3 \%$ and $\mu=0,05$ obtained via interpolation between the values of $\mu=0,03$ and $\mu=0,1$ are as follows:

Table 1 Optimum parameters of TMD

\begin{tabular}{|c|c|c|}
\hline $5 \%$ & $3 \%$ & $\mu$ \\
\hline 0.912 & 0.938 & $\alpha_{\text {opt }}$ \\
\hline 0.1048 & 0.08567 & $\xi_{\text {opt }}$ \\
\hline 20160 & 129500 & $K_{T M D}\left(\mathrm{~kg} / \mathrm{s}^{2}\right)$ \\
\hline 1875 & 955 & $C_{T M D}(\mathrm{~kg} / \mathrm{s})$ \\
\hline 3965 & 2400 & $M_{T M D}(\mathrm{~kg})$ \\
\hline 3.113 & 2.963 & $\mathrm{~T}(\mathrm{sec})$ after TMD installation \\
\hline 0.60 & 0.66 & Maximum ration \\
\hline
\end{tabular}

Figures 8 and 9 represent the absolute roof displacement of a damped structure under the two earthquakes. Comparing Figures 4, 5, 8 and 9 show that the effectiveness of TMD in an undamped structure is more tangible. The reason is that as shown in the diagrams (Fig. 4 and 5), in an undamped structure, due to lack of damping in the structure after starting vibration, the vibration increases and a resonant situation is created. 


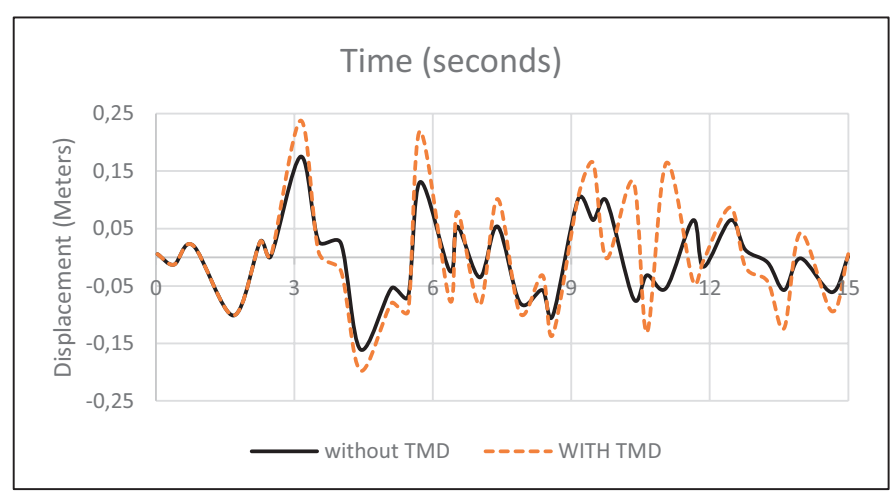

Fig. 4 Roof displacement of a point in undamped structure under El Centro earthquake

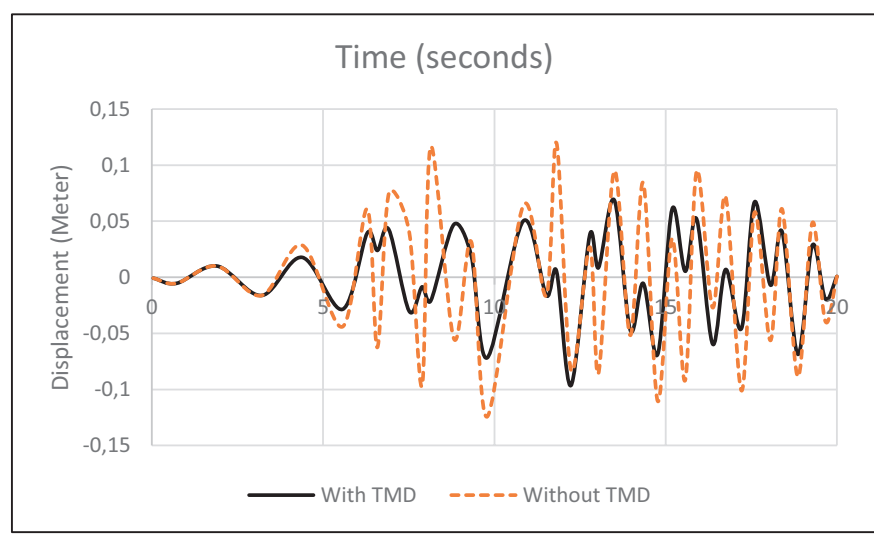

Fig. 5 Roof displacement of a point in undamped structure under Manjil earthquake

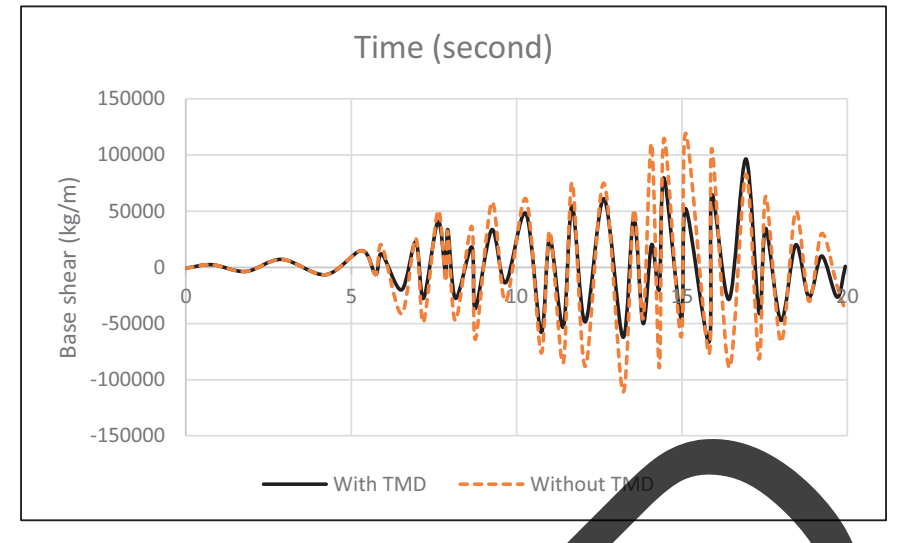

Fig. 7 Base shear in the undamped structure underManjil earthquak

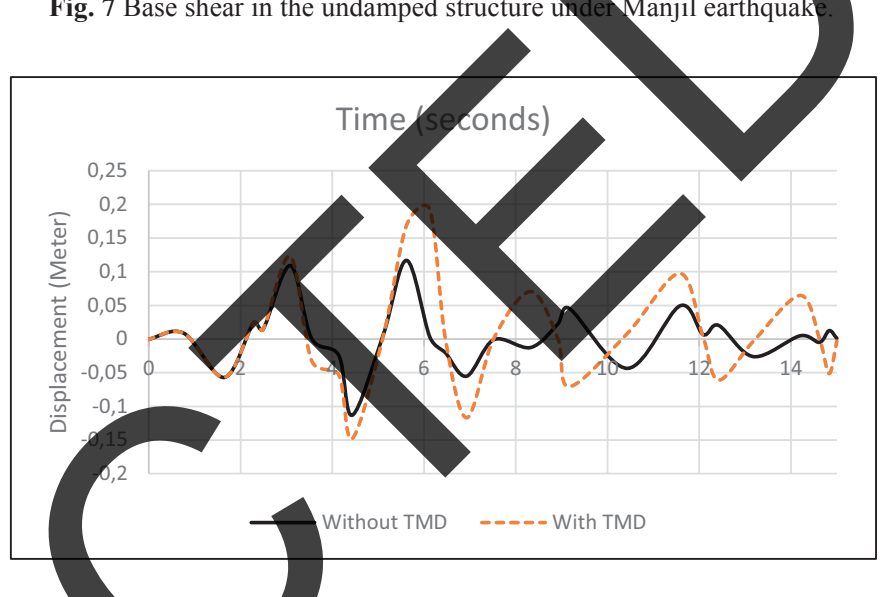

Fig. 8 Roof displacement of a point in the damped structure $\left(\xi_{\mathrm{s}}=5 \%\right)$ under El Centro earthquake

Time (second)

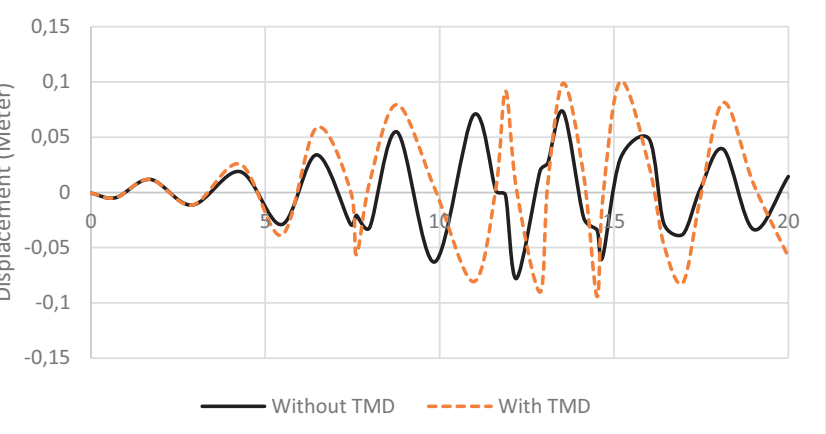

Fig. 9 Roof displacement of a point in the damped structure $\left(\xi_{\mathrm{s}}=5 \%\right)$ under Manjil earthquake
Fig. 6 Base shear in the undamped structure ender El Centro earthquake. Using a TMD significantly dampen these vibrations. How
ine damped structure, damping of the structure itself
reduce the maximums and keep away from a resonant situat
ower and thus the effectiveness of TMD in the structure
nificantly less than in the undamped structure.
4.1 Response of the bridge under train induced
vibration

The external moving point loads that acting on the bridge and the longitudinal distance between axles of the train are shown in Fig. 10. The maximum fast Fourier transform (FFT) acceleration versus speed at midspan of the bridge is shown in Fig. 11. Figure 12 shows the time history of dynamic deflection and their FFT at midspan of the bridge when the train moves over the bridge at the resonant speed. The time histories of dynamic acceleration and their FFT at midspan in directions transverse and vertical directions of the bridge at the speed of $32 \mathrm{~km} / \mathrm{hr}$ and $40 \mathrm{~km} / \mathrm{hr}$ are shown in Fig. 13. The System parameters used in simulation are shown in Table 2.

ISO purposed that maximum sensitivity of human to acceleration in vertical direction is in the frequency range of 4 to $8 \mathrm{~Hz}$ [7]. These excessive vibrations have a disturbing effect on passengers. 


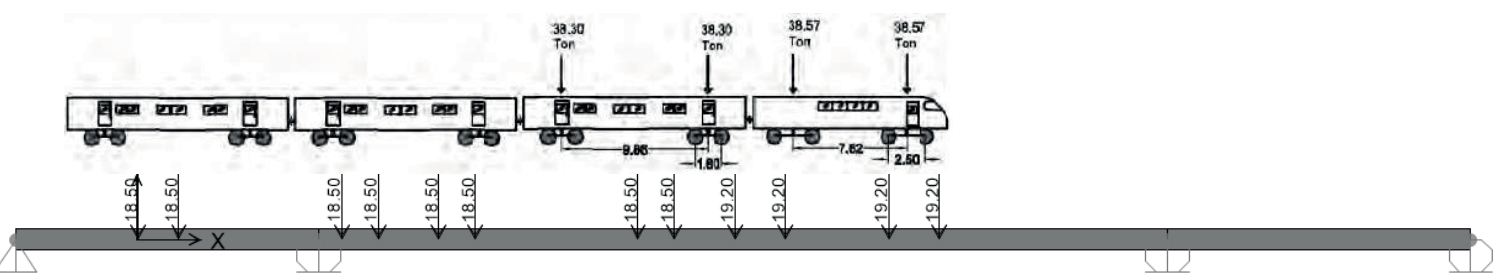

Fig. 10 moving point loads and longitudinal distances between axle of used train (ton-m)

Table 2 System parameters used in simulation.

\begin{tabular}{lll}
\hline System & item & value \\
\hline & Mass $($ ton $/ m)$ & 18 \\
Bridge & main span $(m)$ & 12.0 \\
& Other spans $(m)$ & 10.0 \\
TMD & Damping ratio & $1.0 \%$ \\
& Mass ratio & $2.0 \%$ \\
& Damping ratio & $5.0 \%$
\end{tabular}

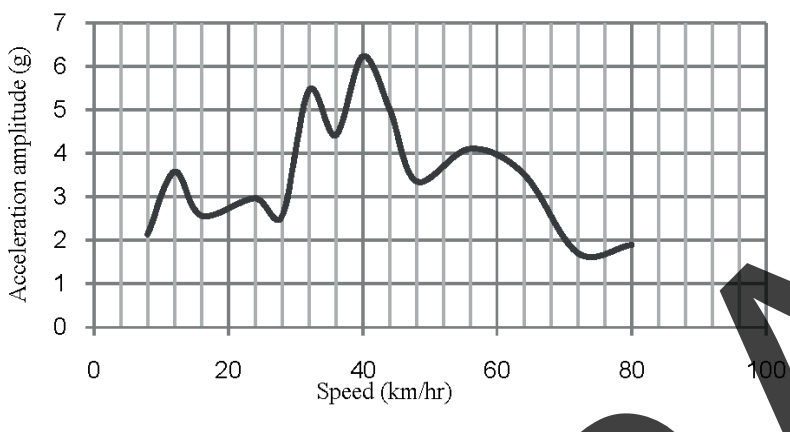

(a)

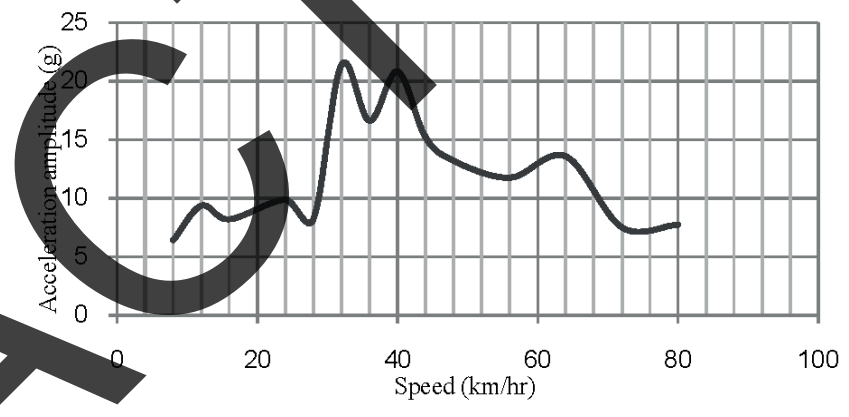

(b)

Fig. 11 Acceleration-speed curves at midspan of bridge without TMD: (a) Transverse direction (b)Vertival direction.
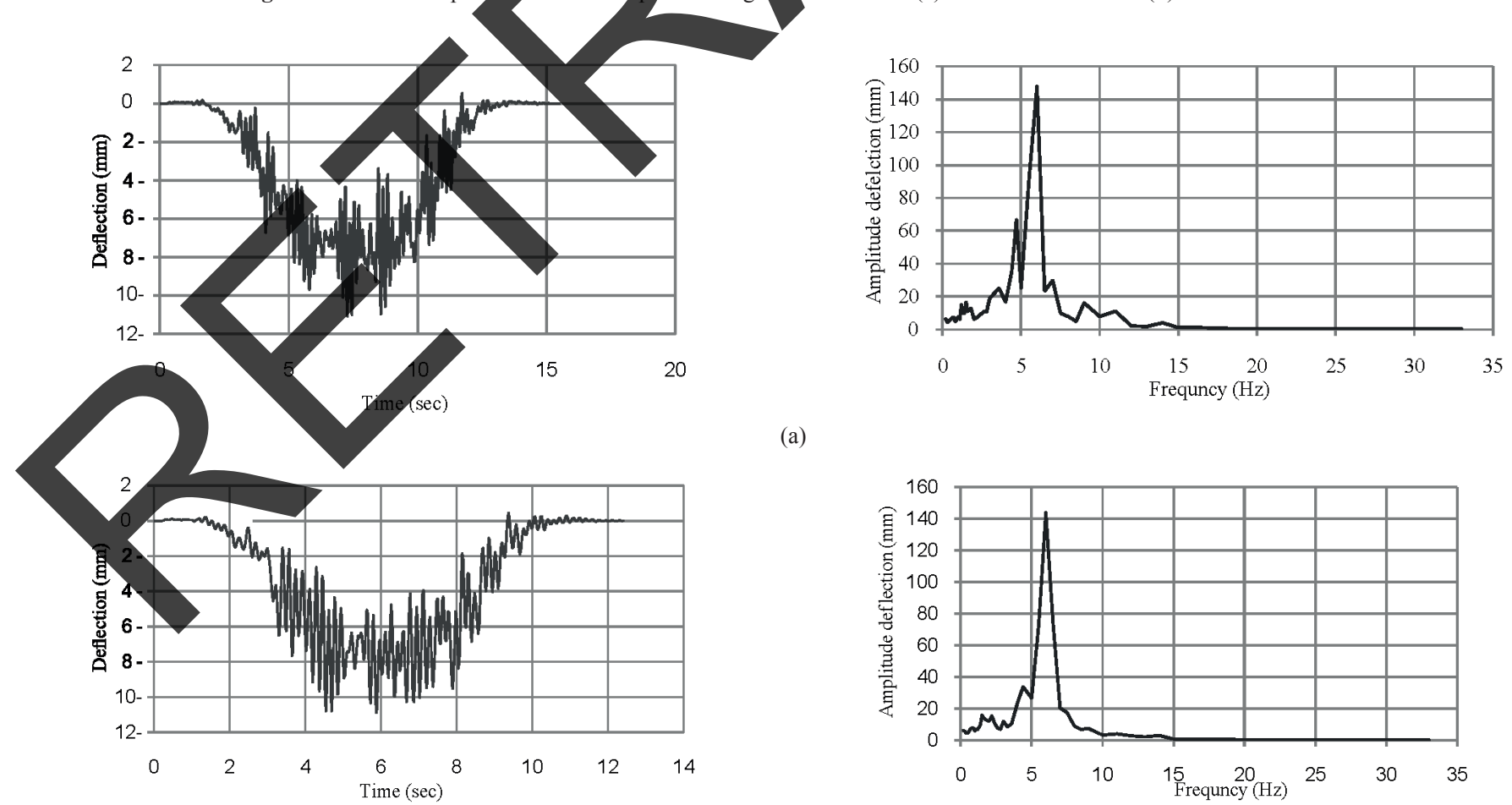

(a)

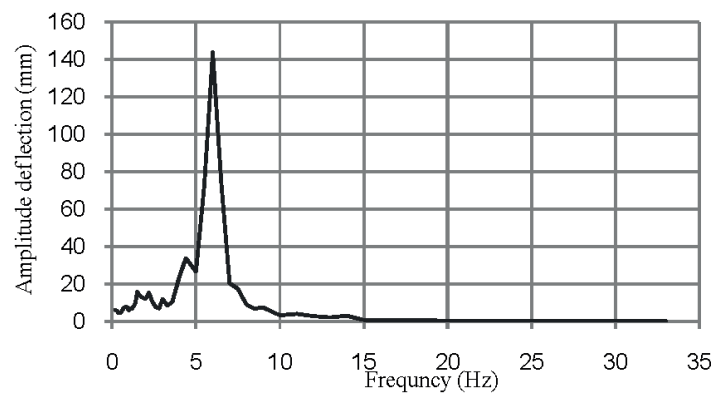

(b)

Fig. 12 Time-histories of vertical deflection and their FFT at midspan of the bridge without TMD: (a) $v=32(\mathrm{~km} / \mathrm{hr})$ and $(\mathrm{b}) v=32(\mathrm{~km} / \mathrm{hr})$ 


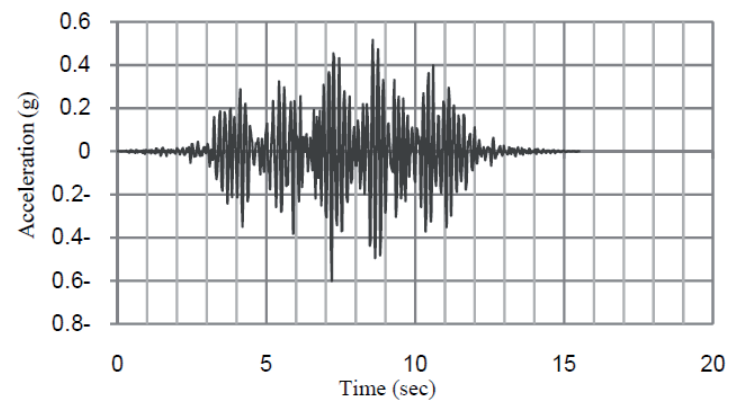

(a)

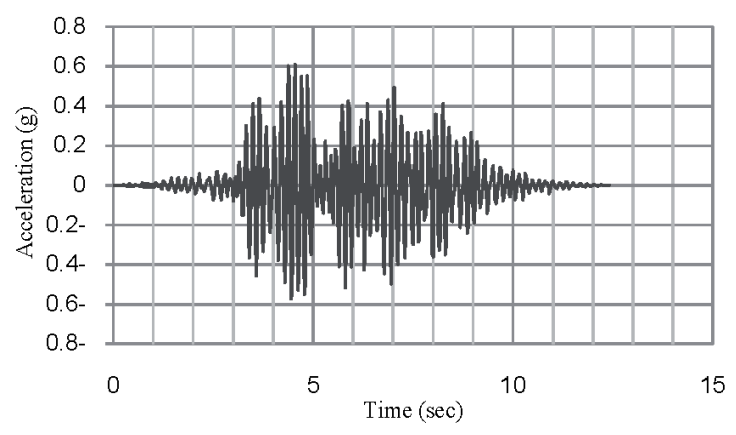

(b)

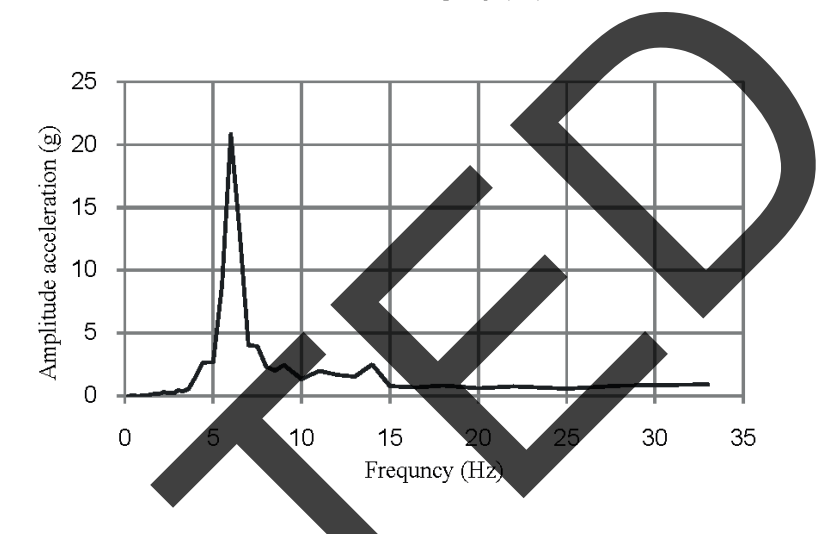

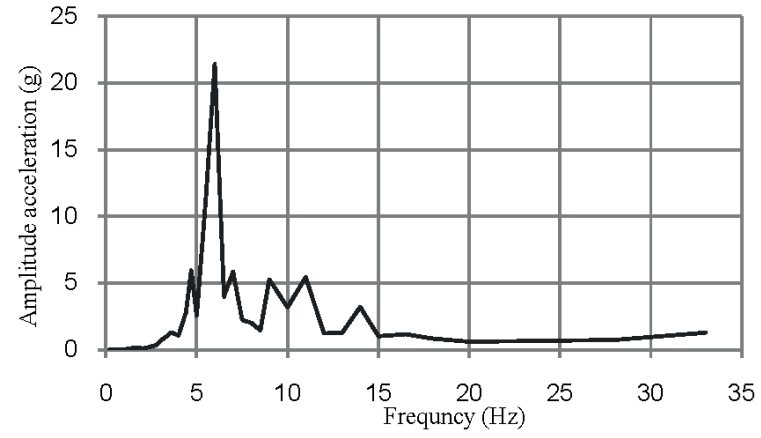

Fig. 13 Time histories of vertical acceleration and their FFT at midspan of the

\section{Response of the bridge with TMD}

In this section, TMD is installed to reduce governing mode of vibrations of the bridge. Governing modes of bridgerare shown in Table 3 . The bridge has very closed two governit modes.
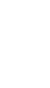


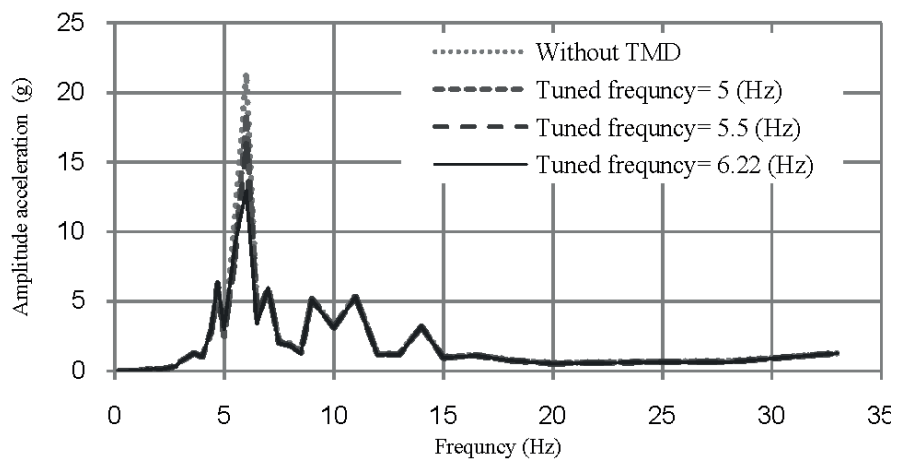

(a)

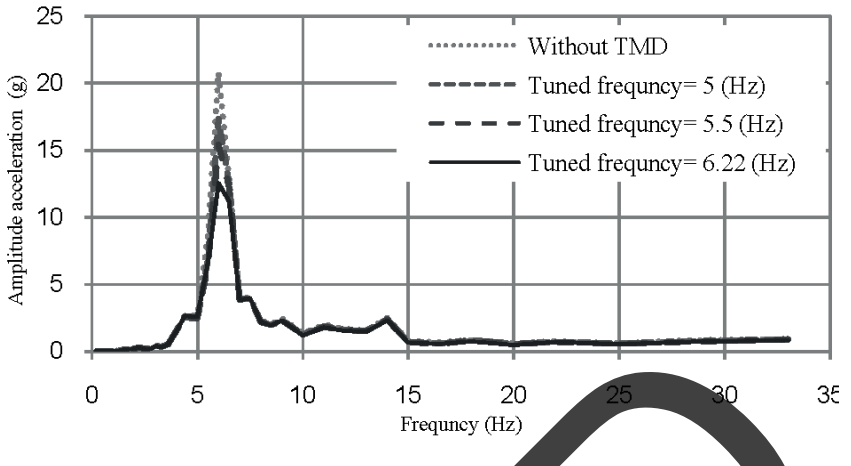

(b)

Fig. 15 Acceleration-frequency curves at midspan of the bridge mass ratio of TMD=0.5\%: (a) $v=32(\mathrm{~km} / \mathrm{hr}) 2 \mathrm{hd}(\mathrm{b}) v=40(\mathrm{~km} / \mathrm{hr})$

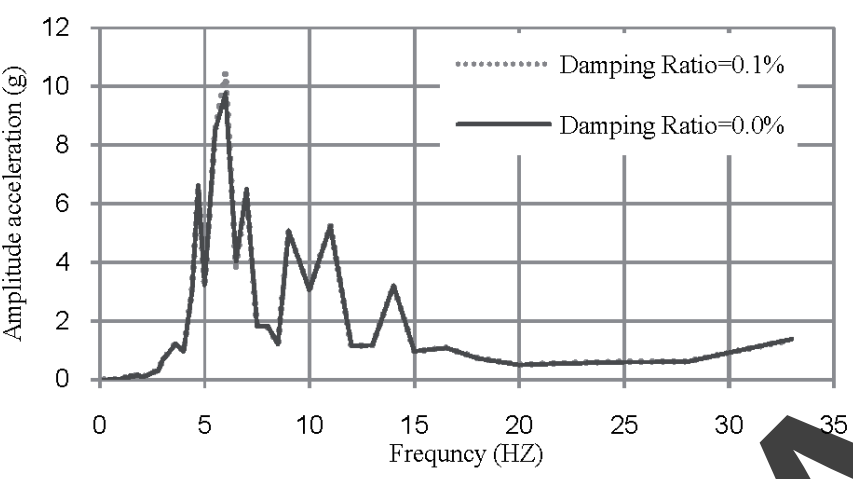

(a)

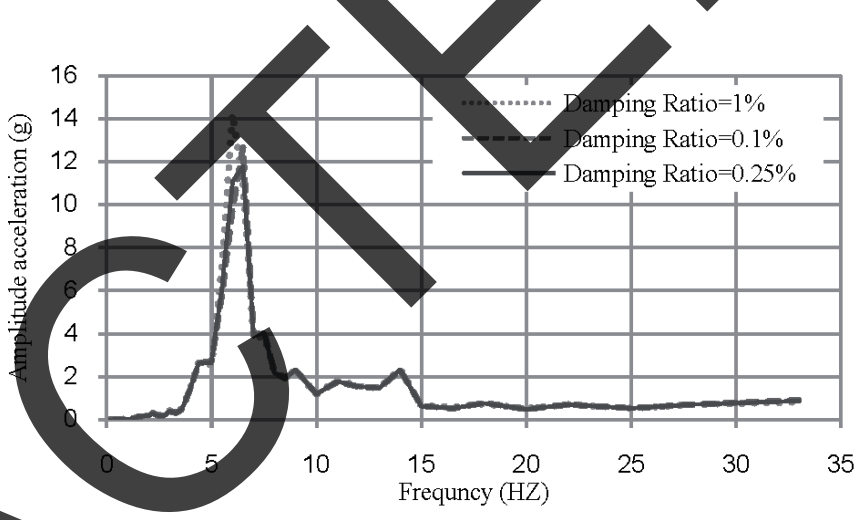

(b)

Fig. 16 Acceleration-frequency curves at midspan of bridge mass ratio of TMD $=0.5 \%$ and tuned frequency $=6.22(\mathrm{HZ}):(\mathrm{a}) v=32(\mathrm{~km} / \mathrm{hr})$ and $(\mathrm{b}) v=40(\mathrm{~km} / \mathrm{hr})$

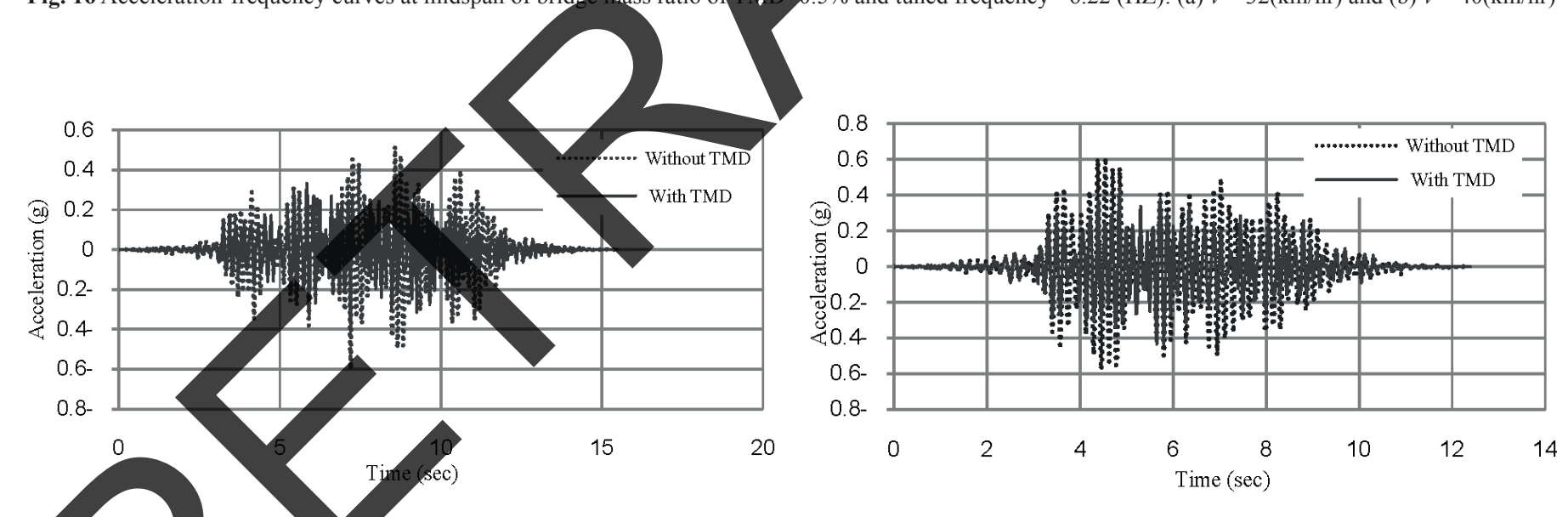

(b)

g. 17 Acceleration-time amplitude response curves at midspan of the bridge mass ratio of TMD=1\% tuned frequency $=6.22(\mathrm{HZ})$ : (a) $v=32(\mathrm{~km} / \mathrm{hr}$ ) and (b) $v=32(\mathrm{~km} / \mathrm{hr})$

\subsection{Effectiveness of TMD for Suppression of Resonant Phenomenon}

The analyzed time-histories of deflection and acceleration at midspan of the bridge at the speed of $32 \mathrm{~km} / \mathrm{hr}$ and $40 \mathrm{~km} / \mathrm{hr}$ are shown in Figs. 17 and 18.
The results of the analyses are summarized in Table 4. The result shows that TMD is effective in reducing acceleration of the bridge, but it has not considerable effect on reducing displacement response of the bridge. 


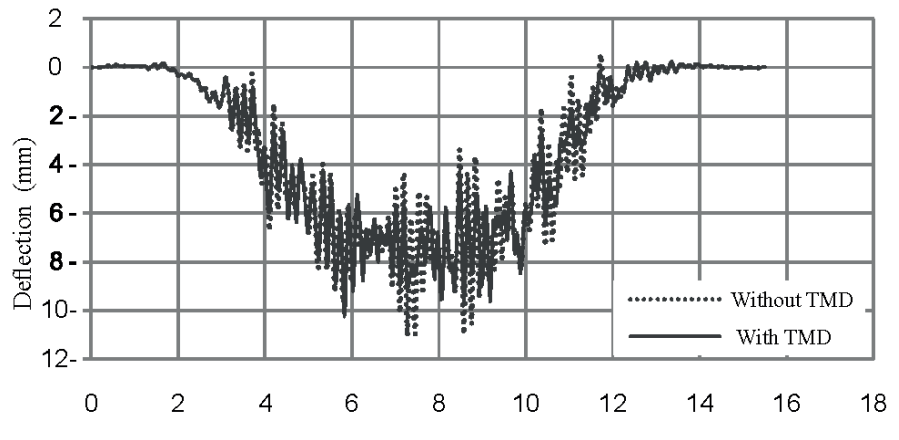

(a)

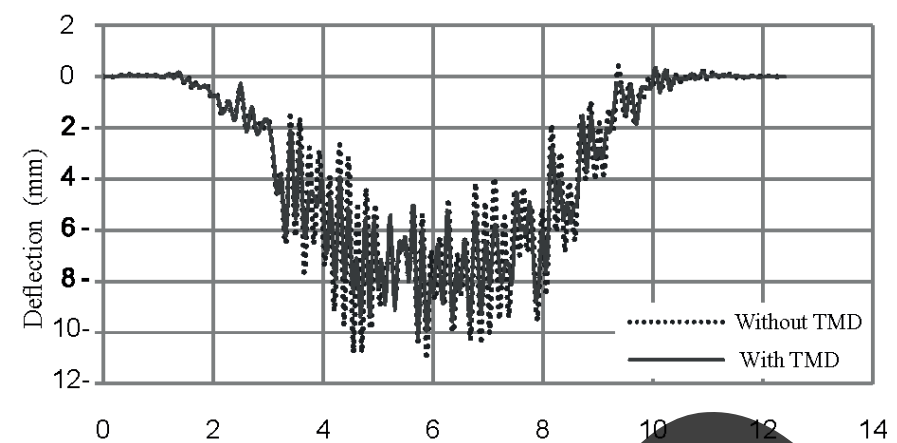

Fig. 18 Deflection-time amplitude response curves at midspan of the bridge mass ratio of TMD=1\% and tur frequency=6.22 (HZ): (a) $v=32(\mathrm{~km} / \mathrm{hr})$ and (b) $v=32(\mathrm{~km} / \mathrm{hr})$

Table 4 maximal response of the bridge with and without TMD

\begin{tabular}{|c|c|c|c|c|c|c|}
\hline $\begin{array}{c}\text { Speed } \\
(\mathbf{k m} / \mathbf{h r})\end{array}$ & TMD Condition & $\begin{array}{l}\text { Maximal vertical } \\
\text { Acceleration (g) }\end{array}$ & $\begin{array}{l}\text { Maximal transv } \\
\text { acceleration (g) }\end{array}$ & & $\ln x$ & $\begin{array}{l}\text { altransverse } \\
\text { ement }(\mathrm{mm})\end{array}$ \\
\hline \multirow{5}{*}{32} & Without TMD & 0.52 & 0.18 & & 3.56 & \\
\hline & TMD With $0.5 \%$ mass ratio & 0.42 & 0.15 & -10.47 & 3.36 & \\
\hline & reduction percentage & 18.24 & 17.0 & & 5.49 & \\
\hline & TMD With $1 \%$ mass ratio & 0.34 & & -10.25 & 3.38 & \\
\hline & reduction percentage & 35.14 & & 3 & 5.17 & \\
\hline \multirow{5}{*}{40} & Without TMD & 0.61 & & -10.89 & 3.28 & \\
\hline & TMD With $0.5 \%$ mass ratio & & & -10.35 & 3.09 & \\
\hline & reduction percentage & & 8.65 & 4.93 & 5.73 & \\
\hline & TMD With $1 \%$ mas & & & -10.23 & 2.98 & \\
\hline & reduction percentage & & 15.78 & 6.07 & 8.96 & \\
\hline
\end{tabular}

\section{Conclusion}

The results of this study show the tangible and positive effect of TMD on struetural vibrations. The important point regarding the effectiveness of TMO is the dominance of a mode in the structure (first mode), for which the TMD is designed and installed Certainly, those relations work better for SDOF structures and the TMD designed for these structures perform better. Therefore, high-rise SDOF structures with more concentrated mass in high altitude such as telecom towers are the best choice for TMDs to reduce the vibrations caused by wind and earthquake in them. Other results show more effectiveness of TMD system in undamped structures. Regarding the behavior of the TMD it should be noted that the damper is activated after the first maximum input load (or acceleration) and has the ability to control the next maximums. Thus, the ratio of maximum displacement of the system with TMD to that of a system without TMD depends on the shape of the input record (earthquake).
In this second case study, TMD is used to suppress the vibration of Shazand Railway Bridge under passing train. The performance of TMD with parameters of the tuned frequency, damping ratio and mass ratio are investigated. From the results the following conclusions may be drawn:

- When natural frequencies of the bridge are multiples of the frequency of the train excitation, the resonant effect will occur and cause excessive vibrations of the bridge.

- The bridge has two close natural modes that cause two close resonant speeds. The resonant speeds of tested trains are $32 \mathrm{~km} / \mathrm{hr}$ and $40 \mathrm{~km} / \mathrm{hr}$.

- TMD with optimum parameter, significantly reduces acceleration of the bridge, but it has not very effective in suppressing deflection of the bridge. 


\section{Acknowledgments}

The work was executed with financial support from petrochemical industries development Management Company of the Iran.

\section{References}

[1] Frahm, H. "Device for Damping Vibrations of Bodies." US patent \#989958. 1909.

[2] Den Hartog, J. P. "Mechanical Vibration." New York: McGraw-Hill. 1956.

[3] Kwon, H.C., Kim, M.C., Lee, I. W. "Vibration control of bridges under moving loads." Computers and Structures. 66 (4). pp. 473-480. 1998. DOI: 10.1016/s0045-7949(97)00087-4

[4] Wang, J. F., Lin, C. C., Chen, B. L. "Vibration suppression for highspeed railway bridges using tuned mass dampers." International Journal of Solids and Structures. 40 (2). pp. 465-491. 2003. DOI: 10.1016/s0020-7683(02)00589-9

[5] Jianzhong, L., Mubiao, S. "The resonant vibration for a simply supported girder bridge under high speed trains." Journal of Sound and Vibration. 224 (5). pp. 897-915. 1999. DOI: 10.1006/jsvi.1999.2226

[6] Sadek, F., Mohraz, B., Taylor, A. W., Chung, R. M. "A Method of Estimating the Parameters of Tuned Mass Dampers for Seismic Applications." Earthquake Engineering and Structural Dynamics. 26 (6). pp. 617-635. 1997.

DOI: 10.1002/(sici)1096-9845(199706)26:6<617::aid-eqe664>3.0.co;2-z

[7] International organization for standards. "Evaluation of human exposure to whole-body vibration _ part 2: Continuous and shock-induced vibration in buildings (1_80 Hz)." Geneva (Switzerland): International standard ISO- 2631/2- (E). 1989.
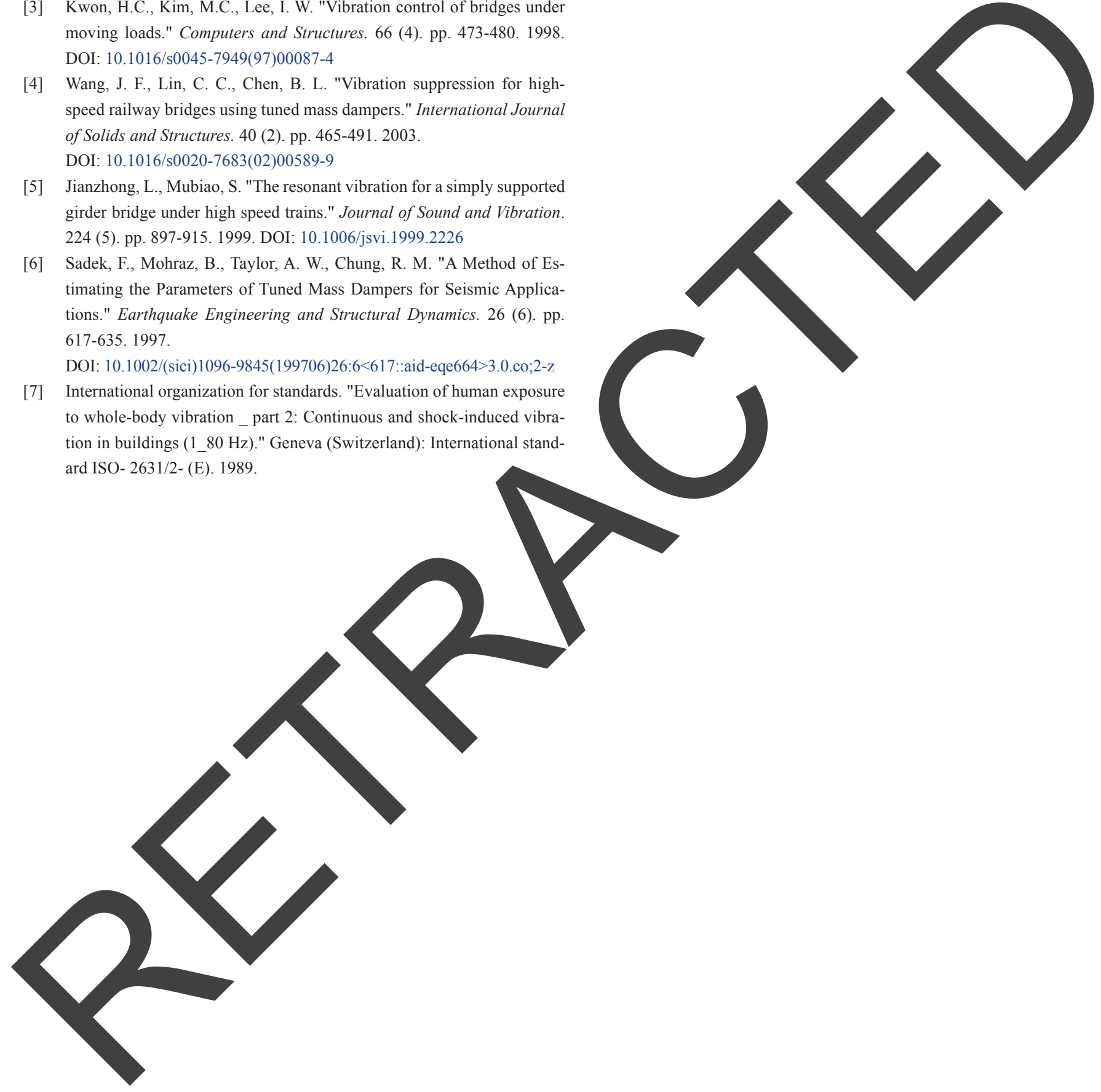